The religious agency of women in the narrative of Unamuno

\title{
La agencia religiosa de la mujer en la narrativa de Unamuno
}

Rodolfo GuTIÉRRez SimóN

(Universidad Complutense de Madrid) rodolfo.gutierrez@ucm.es

DOI: https://doi.org/10.15366/bp.2020.24.002

Bajo Palabra. II Época. No 24. Pgs: 37-54

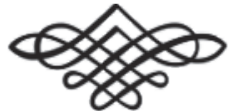


Recibido: 27/07/2020

Aprobado: $12 / 08 / 2020$

Este trabajo ha sido posible gracias a la financiación del proyecto "La Biblioteca Digital de Pensamiento Político Hispánico Saavedra Fajardo” (Fundación BBVA - Ayudas Fundación BBVA a equipos de investigación científica 2018).

\section{Resumen}

El propósito de este estudio es analizar las dimensiones de agencia religiosa que la mujer desempeña en las novelas de Unamuno. Para ello, se ofrece una visión de algunos puntos esenciales de la filosofía unamuniana y se aborda la concepción de la maternidad biológica y virginal que el autor desarrolla. A partir de este análisis se investiga el papel de agente religioso que algunos personajes femeninos juegan en sus novelas para, finalmente, reflejar un acontecimiento de la biografía de Unamuno que complementa su planteamiento teórico.

Palabras clave: Unamuno; mujer; maternidad; religión; literatura.

\section{Abstract}

The aim of this paper is to investigate some levels of religious agency that women play in Unamuno's novels. it offers an overview of some essential points of the author's philosophy, specifically the author's conception of biological and virginal motherhood. From this analysis, the role of religious agent that some female characters play in their novels is investigated. Finally, the research about an event in the author's biography will complement his theoretical approach.

Keywords: Unamuno; women; motherhood; religion; literature. 


\section{Introducción}

Aunque EXISTEn trabajos en los que se pormenoriza el papel de los distintos personajes femeninos en la narrativa de Unamuno ${ }^{1}$, no se ha solido destacar la agencia religiosa de algunos de ellos. Lo que se pretende resaltar en este estudio no es sólo el nivel de intervención religiosa de algunos de dichos personajes, sino la necesidad de que sean mujeres las que los encarnen dentro del marco filosófico general del autor. Para ello, se atenderá especialmente a esa dimensión concreta de la feminidad unamuniana que es la maternidad espiritual. En este contexto, la investigación se centrará ante todo en los personajes femeninos de la novelística del autor, y sólo al final se aludirá como apoyo a un conocido momento de su biografía en que la relación con las mujeres -en concreto, con su esposa- condicionó los presupuestos de dicha obra narrativa ${ }^{2}$.

\section{La maternidad (biológica y espiritual) en el marco filosófico general de Unamuno}

De ENTRE LOS MUCHOS TEMAS que preocuparon al autor vasco, no cabe duda de la centralidad del problema metafísico y religioso de la inmortalidad, el deseo irrenunciable de todo hombre (y de toda mujer) de no morirse, de perpetuarse en el tiempo indefinidamente. Conviene aclarar desde el principio cierto matiz que puede resultar confuso. Si nos atenemos a los primeros capítulos de la obra filosófica más relevante del autor, Del sentimiento trágico de la vida en los hombres y en

\footnotetext{
${ }^{1}$ Cf. Morales Galán, C., El tema maternal en la concepción unamunesca de la mujer, Tesis doctoral, Louisiana State University and Agricultural and Mechanical College, 1971.

2 Para un análisis detallado de las relaciones personales con las mujeres -además de las que específicamente se mencionarán más abajo en el cuerpo del texto-, puede consultarse Sandoval Ullán, A., "El concepto de mujer en el pensamiento de Miguel de Unamuno", en Cuadernos de la Cátedra Miguel de Unamuno, 39, 2004, pp. 27-60; texto con el que, no obstante, mantengo algunas discrepancias de enfoque cuando aborda (a partir de la página 42) el tema de la mujer desde el plano teórico (habida cuenta de que emplea en ocasiones un tono más próximo al ensayo que al análisis académico, dicho sea esto sin ningún sesgo peyorativo y sin infravalorar las numerosas citas que el artículo aporta). Asimismo es muy destacable el proyecto en curso "Bajo pluma de mujer", dirigido por Maribel R. Fidalgo, a propósito de la correspondencia femenina de Unamuno; cf. https://bajoplumademujer.wixsite.com/bajoplumademujer. Por otra parte, y de manera complementaria a este estudio, puede verse la interesante categorización de personajes femeninos que lleva a cabo José Carlos Mainer en su "Introducción" a Unamuno, M., La tía Tula, Madrid: Alianza, 2012, pp. 18-20.
} 
los pueblos, se aprecia que este anhelo de eternidad no está estrictamente ligado a la inmortalidad del alma. Así, es muy conocida la referencia unamuniana al "hombre de carne y hueso" que es cada filósofo y que late tras las ideas: por mucho que Descartes pretendiese reducir su personalidad a res cogitans inextensa, el hecho es que hubo un René Descartes que tenía un cuerpo y unas preocupaciones, que escribía desde su cama, arropado y protegido del frío por una estufa, etc. Pues bien: es el hombre de carne y hueso el que quiere eludir la total desaparición, el que no quiere que su conciencia o su alma sigan navegando por quién sabe qué remotos parajes tras la muerte. El deseo del hombre real es, siempre según Unamuno, vivir siendo él siempre, con su cuerpo y su carácter. Del mismo modo, aunque la cuestión reaparecerá más adelante, tampoco parece conformarse Unamuno con la perpetuación genética o con la fama por la fama misma. Así, en Del sentimiento trágico... se lee:

"Todo eso de que uno vive en sus hijos, o en sus obras, o en el Universo, son vagas elucubraciones con que sólo se satisfacen los que padecen de estupidez afectiva, que pueden ser, por lo demás, personas de una cierta eminencia cerebral. Porque puede uno tener un gran talento, lo que llamamos un gran talento, y ser un estúpido del sentimiento y hasta un imbécil moral. Se han dado casos" ${ }^{3}$.

Dado que probablemente Unamuno no se tenía a sí mismo por un imbécil afectivo, resulta legítimo pensar que su renuncia a esa triste continuidad parcial de la existencia era auténtica.

Así las cosas, y aunque de manera excesivamente esquemática, queda destacado el papel fundamental que tiene para este autor, dentro de su marco teórico, el tema de la inmortalidad y el hambre que necesariamente todos (no sólo Unamuno) tendríamos de ella ${ }^{4}$. Y ha de recalcarse el todos: en opinión del escritor vasco, nadie quiere morirse ${ }^{5}$. En este sentido es oportuno recurrir por primera vez a uno de los textos que van a protagonizar este análisis: San Manuel Bueno, mártir. En el sexto capítulo, la narradora, Ángela -que no se llama así por casualidad según se aclarará más abajo- relata un pasaje de la vida de San Manuel muy revelador. En dicho texto, el padre de un suicida pregunta al sacerdote si dará sepultura a su hijo (habida cuenta de la condenación eterna a que están destinados los que se quitan la vida). A

${ }_{3}$ Unamuno, M., Del sentimiento trágico de la vida en los hombres y en los pueblos, en Obras Completas VII, Madrid, Escelicer, 1967, p. 119.

${ }^{4}$ Véase Senabre, R., "Introducción”, en Unamuno, M. Obras completas I, Madrid, Fundación José Antonio de Castro, 1995, p. XIV.

5 El verbo querer está aquí perfectamente usado, pues es el que aparece en fragmentos tan claros como este: "En una palabra: que con razón, sin razón o contra ella, no me da la gana de morirme. Como no llegue a perder la cabeza, o mejor aún que la cabeza, el corazón, yo no dimito de la vida: se me destituirá de ella” (Unamuno, M., Del sentimiento trágico de la vida en los hombres y en los pueblos, op. cit., p. 186). La cursiva es mía. 
ello responde el cura: "Seguramente, pues en el último momento, en el segundo de la agonía, se arrepintió sin duda alguna" ${ }^{6}$. Hasta los que no quieren vivir anhelan vivir para siempre.

Más adelante se analizará qué puede tener que ver este asunto con la mujer, y en concreto con algunos personajes femeninos de las novelas unamunianas Amor y pedagogía, La tía Tula y San Manuel Bueno, mártir.

Conviene ahora, todavía contextualizando la presencia femenina en las obras unamunianas, aludir brevemente a uno de esos conceptos problemáticos y polémicos cuando se ha de abordar el papel de la mujer en cualquier ámbito de la vida: el amor. Por supuesto, una aproximación adecuada al tema del amor en Unamuno requeriría mucho más espacio del que ahora puede emplearse; por tanto, serán señalados sólo los detalles imprescindibles para sostener el argumento de este artículo. En primer lugar, es preciso recuperar de nuevo una cita de Del sentimiento trágico... que permite establecer sin dificultad el vínculo entre el amor y la eternidad, que ocupó los primeros compases de esta investigación:

“Eternidad! ¡Eternidad! Éste es el anhelo; la sed de eternidad es lo que se llama amor entre los hombres, y quien a otro ama es que quiere eternizarse en él. Lo que no es eterno tampoco es real" 7 .

Aquí está una de las claves que no se deben confundir. Anteriormente se ha indicado que para Unamuno es insuficiente la perpetuación eterna a través, por ejemplo, de los hijos: su pretensión en tanto que individuo -y la de todos los demás según su doctrina-, es mantenerse él. Sin embargo, en esta cita, que parece apuntar en dirección contraria, se deja ver un cierto desdoblamiento de la persona: hay eternización de uno en el ser amado, no porque sea amante o hijo (si es que de un hijo se trata) realmente, sino porque se le ama. Este ligerísimo matiz será fundamental en esta investigación, pues la maternidad (atributo femenino esencial ${ }^{8}$ que, como se verá, puede ser llevado a cabo por hombres) va a jugar un papel religioso determinante en la obra del rector vitalicio de Salamanca?.

Curiosamente, es un personaje masculino el que pone en claro de la forma más nítida el amor del que aquí se está hablando: el Quijote de Vida de Don Quijote

\footnotetext{
${ }^{6}$ Unamuno, M., San Manuel Bueno, mártir y tres historias más, en Obras Completas II, Madrid, Fundación José Antonio de Castro, 1995, p. 320.

7 Unamuno, M., Del sentimiento..., op. cit. p. 132.

${ }^{8}$ Cf. Pacheco, B., "La concepción de lo femenino en Unamuno: encuentro en un entreacto", en Contexto, Segunda Etapa, volumen 8, no 10, 2004, p. 220.

9 Esto no significa que para Unamuno el amor carnal o sexual sea el punto de arranque de cualquier otro. Como digo, el tema excede con mucho el propósito aquí; no obstante, si hubiera que remitir al lector a algún punto concreto, sería el séptimo capítulo de Del sentimiento trágico de la vida..., op. cit., pp. 187 ss. En esas páginas queda además vinculado el amor con otro tema decisivo en su obra y colindante con lo aquí abordado: la muerte.
} 
y Sancho. Aunque en algunos pasajes de En torno al casticismo ya aparece cierta caracterización del amor castellano ${ }^{10}$, la relación entre Don Quijote y Dulcinea, y más aún la existente entre Alonso Quijano el Bueno y Aldonza Lorenzo, resulta de claridad superlativa. Este breve fragmento de la obra, por ejemplo, permite vincular con sencillez el amor con la inmortalidad y con otro de los temas centrales para Unamuno: el heroísmo.

"Ved aquí cómo del amor a mujer brota todo heroísmo. Del amor a mujer han brotado los más fecundos y nobles ideales, del amor a mujer las más soberbias fábricas filosóficas. En el amor a mujer arraiga el ansia de inmortalidad, pues es en él donde el instinto de perpetuación vence y soyuga al de conservación, sobreponiéndose así lo sustancial a lo meramente aparencial. Ansia de inmortalidad nos lleva a amar a la mujer, y así fue como Don Quijote juntó en Dulcinea a la mujer y a la Gloria, y ya que no pudiera perpetuarse por ella en hijo de carne, buscó eternizarse por ella en hazañas de espíritu. Fue enamorado, pero de los castos y continentes, como dijo en otra ocasión él mismo. ¿Faltó con su castidad y continencia al fin del amor? No, pues engendró en Dulcinea hijos espirituales duraderos. Casado no podría haber sido tan loco; los hijos de carne le hubieran arrebatado de sus hazañosas empresas" ${ }^{11}$.

Es bien conocido el hecho de que Unamuno, lejos de querer mostrarse como un pensador diáfano y consecuente en sus exposiciones, prefería proponer contradicciones que hicieran aflorar en el lector la síntesis aclaradora ${ }^{12}$. Estamos ante uno de esos casos, aunque quizá no se ha insistido con suficiencia sobre él: el amor que acompaña a la inmortalidad es casto; la maternidad verdaderamente significativa ha de ser en alguna medida una maternidad virginal. Y no es casualidad que se utilice recurrentemente este adjetivo: Unamuno dará a la Virgen un papel quizá más relevante que a Dios; una Virgen que, obviamente, tiene entre sus rasgos distintivos el de ser madre y el de ser mujer ${ }^{13}$ (rasgos que en la obra y novela unamunianas aparecen indisolublemente unidos $\left.{ }^{14}\right)$. Tanto es así que Unamuno imputará implí-

\footnotetext{
${ }^{10}$ Aunque hay muchos lugares en que puede apreciarse esta idea, cf. especialmente: Unamuno, M., En torno al casticismo, en Obras Completas VIII, Madrid, Fundación José Antonio de Castro, 2007, p. 98.

11 Unamuno, M., Vida de Don Quijote y Sancho, en Obras Completas III, Madrid, Escelicer, 1968, p. 98.

12 "Como que sólo vivimos de contradicciones y por ellas; como que la vida es tragedia, y la tragedia es perpetua lucha, sin victoria ni esperanza de ella; es contradicción” (Unamuno, M., Del sentimiento trágico..., op. cit., p. 117).

13 Aunque en todo lo que sigue me referiré a La tía Tula siguiendo la edición Unamuno, M., La tía Tula, en Obras completas I, Madrid, Fundación José Antonio de Castro, 1995, es menester indicar que sobre la mujer virginal y madre a la vez en el esquema de la contradicción unamuniana puede verse el "Prólogo" de Manuel Hidalgo a Unamuno, M., La tía Tula, Barcelona, Bibliotex SL, 2001, p.5. También ocurre a la inversa: toda madre es virgen (cf. Unamuno, M., Abel Sánchez: una historia de pasión, en Obras completas I, Madrid, Fundación José Antonio de Castro, 1995, p. 728).

${ }^{14}$ En La tía Tula se lee: "Toda mujer nace madre" (Unamuno, M., La tía Tula, en Obras completas I, Madrid, Fundación José Antonio de Castro, 1995, p. 817); y así en otros lugares, como el "Epílogo" al drama El otro.
} 
citamente a Dios una serie de características (negativas) típicamente masculinas ${ }^{15}$, si bien esta caracterización de lo masculino ha de entenderse como ideal teórico genérico: algunos de sus personajes masculinos no los encarnan. En esos casos excepcionales, no obstante, suele haber una feminización del varón en tanto que se le atribuyen cualidades simbólicamente femeninas en el imaginario literario de Unamuno: por ejemplo, Ángela Carballino se refiere a San Manuel como "varón matriarcal" ${ }^{16}$, mientras que son obvios los valores matriarcales del tío sacerdote de Tula y Rosa.

Así, y pese a excepciones como las nombradas, Unamuno propone frente al Dios andromórfico, guerrero y vengador, a la Virgen mujer y madre que perdona, consuela ${ }^{17} \mathrm{e}$ incluso salva ${ }^{18}$. Entendidos como "padre" y "madre" respectivamente estos arquetipos, puede llevarse este contraste a ejemplos narrativos. La diferencia resulta particularmente clara al comparar a Avito Carrascal, padre de Apolodoro en Amor y pedagogía con doña Soledad, madre de Augusto Pérez en Niebla: si ésta detestaba los latinajos con los que se caracteriza científicamente a los animales y, en cambio, leía a su hijo las obras fantásticas de Julio Verne ${ }^{19}$, aquél insistía a su hipotético genio futuro en la nomenclatura latina de la biología a la par que renegaba de los libros del autor francés ${ }^{20}$. Que sean exactamente estos dos ejemplos (uso del latín y Julio Verne) los que aparecen en Niebla tras antes haber sido mencionados en Amor $y$ pedagogía no puede ser en modo alguno una casualidad. Y menos si tenemos en cuenta ciertos pasajes del "Prólogo" a La tía Tula, donde paternidad y maternidad se diferencian, así como fraternidad y sororidad ${ }^{21}$.

\section{La agencia religiosa femenina en la literatura de Unamuno: algunos ejemplos}

A paRTIR DE ESTOS MIMBRes, es posible abordar el estudio de algunos personajes femeninos de la literatura unamuniana. En este sentido, y aunque no sean los únicos posibles, resultarán ejemplos paradigmáticos para el argumento propuesto 1) Ma-

\footnotetext{
${ }_{15}$ La vinculación Dios-virilidad frente a la maternidad aparece de forma muy clara en La agonía del Cristianismo, op. cit., p. 73. Asimismo, puede ser interesante en este punto destacar la distinción que Tula realiza entre el hombre y el macho, siendo éste la cara negativa de aquél (cf. La tía Tula, op. cit., p. 869).

16 San Manuel Bueno, mártir, op. cit., 313.

17 Unamuno, M., Vida de Don Quijote y Sancho, op. cit., pp. 233-234.

${ }^{18}$ Cf. Unamuno, M., Abel Sánchez, op. cit., p. 732; y el pasaje en el que Tula se arroga el deber de salvar almas (cf. La tía Tula, op. cit., p. 816)

19 Unamuno, M., Niebla, en Obras completas I, Madrid, Fundación José Antonio de Castro, 1995, pp. 507-508.

${ }^{20}$ Unamuno, M., Amor y pedagogía, en Obras completas I, Madrid, Fundación José Antonio de Castro, 1995, p. 362.

${ }^{21}$ Cf. Unamuno, M., La tía Tula, op. cit., p. 799.
} 
rina del Valle, de Amor y pedagogía; 2) Tula, de La tía Tula; y 3) Ángela Carballino, de San Manuel Bueno, mártir. En ellas se aprecian tres niveles de agencia religiosa coherentes con la filosofía unamuniana, y es de sumo interés tratar de dilucidar por qué han de ser necesariamente mujeres quienes encarnen dichos papeles.

Aunque son textos bien conocidos, es preciso poner en situación a cada uno de estos personajes, destacando después el nivel de agencia religiosa que pueda tener en relación con lo que hasta aquí se ha expuesto. En primer lugar, Marina del Valle es la esposa de Avito Carrascal, el estrambótico protagonista de Amor y pedagogía. Aunque Unamuno no acostumbra a describir físicamente a las personas, podemos inferir que Marina posee un atractivo fuera de lo común. Tanto es así, que Avito -un positivista spenceriano cuyo objetivo vital era tener un hijo genio- viola su propio método de elección de esposa: en lugar de casarse con la que deductivamente ofrecía mayores garantías para ser madre de un prodigio (Leoncia), se empareja inductivamente con Marina ${ }^{22}$, a la que se considerará en ocasiones como "la materia", necesitada de "la forma" (Avito) que le dote de estructura y sentido ${ }^{23}$.

Marina y Avito, materia y forma, amor y pedagogía. No es casualidad que se puedan realizar estas tres conjunciones o parejas; al contrario, de ello depende la novela. Es preciso, llegado este punto, plantearse una pregunta y su posible respuesta: parece razonablemente clara la diferencia entre Marina y Avito, entre hombre y mujer, entre materia y forma; pero... ¿ ¿n qué medida es el amor lo opuesto a la pedagogía? Aquí radica el meollo del texto. La "pedagogía" encarnada por Avito es un cientificismo extremo, en el que todo está sujeto a medida y a número. Incluso lo que no es susceptible de ser cuantificado tiende a analizarse científicamente. En este sentido, uno de los aspectos más curiosos y significativos de la novela tiene que ver con el nombre que el futuro genio ha de llevar. El padre, Avito, considera como científicamente necesario que el joven porte un nombre con significado ${ }^{24}$. Este detalle, aparentemente superfluo, está en realidad subyacido por una tesis fuerte. Así, Avito decide que el nombre adecuado para el genio potencial es Apolodoro, literalmente "el don de Apolo". Por una parte, es cierto que Apolo no deja de ser, junto a Asclepio, el dios de la ciencia y los médicos; por otra, supone una cierta concesión a los dioses, aunque sean paganos. Lo verdaderamente relevante, sin embargo, no es eso; lo que importa es que Marina, siempre que Avito no está delante, llama al niño

${ }^{22}$ La categorización inductivo-deductivo respecto al amor es de Unamuno. Véase el capítulo I de Amor y pedagogía (op. cit., pp. 315 ss.).

23 El propio Unamuno declara que, aunque invirtiendo los papeles de materia y forma, el antecedente de esta idea es Les femmes savantes de Molière (cf. el "Epílogo" a Amor y pedagogía, op. cit., p. 429).

${ }^{24}$ Unamuno, M. Amor y pedagogía, op. cit., p. 332. Es muy interesante, en la edición de Anna Caballé (Madrid, Austral, 2007), la nota 4 que acompaña a la cita propuesta (p. 78) en que se desglosa brevemente el interés de Unamuno por la onomástica y cómo juega con ella al dar nombre a sus personajes. 
por otro nombre: Luis. Así se llamaba el abuelo materno del niño, y tal es el nombre de bautismo del bebé (nombre que será "el nombre prohibido, el vergonzante, el íntimo" 25, frente al "racional" Apolodoro).

¿Qué relación tiene todo esto con el tema aquí analizado? En primer lugar, es el ejemplo que con mayor claridad permite mostrar cómo la mujer encarna el valor típicamente religioso de la tradición ${ }^{26}$ : Marina -frente a la constante apuesta de Avito por las "leyes nuevas" ${ }^{27}$ - no sólo pone al niño un nombre absolutamente tradicional en nuestro país, sino que es el nombre del abuelo, señal evidente de lo que se pretende. Además, es el nombre de bautismo, no el "legal" u oficial: es el apelativo por el que el niño será conocido en el reino de Dios, no en el de los hombres. Dicho sea de paso: tampoco es legal el nombre "Tula", apelativo con el que se conoce a Gertrudis en La tía Tula. Resulta evidente que los nombres "Tula" o "Luis" sólo se utilizan cuando existe una recíproca apertura entre el mentado y el que menciona: Marina-Luis, Tula-sobrinos, etc. Cuando la apertura es unidireccional, en cambio, se emplea el nombre legal, despojado de afectividad (Apolodoro, Gertrudis). La importancia del nombre y su relación con el bautismo no es, en suma, algo trivial en la novela unamuniana; prueba de ello es que reaparece en otros lugares ${ }^{28}$. Y a todo ello se añade, sutilmente, algo significativo: Marina trae lo tradicional (el ancestro, el abuelo) al presente (el niño). Con ello cumple una idea de En torno al casticismo que no siempre se realza, a saber: que la tradición, aunque proceda del pasado, llega necesariamente a la actualidad, trayendo hasta el momento corriente lo pretérito ${ }^{29}$. La eternidad, que fue el punto de arranque de esta investigación, no sólo tiende hacia el futuro: se puede traer hasta aquí una eternidad pasada.

Hecho el largo inciso anterior, procede recuperar la pregunta que previamente quedó en el aire: ¿en qué sentido es el amor lo contrario a la pedagogía? Ya puede intuirse la respuesta: el amor es el ámbito de lo incuantificable, de lo pasional, de lo afectivo, y en este sentido, de lo religioso; necesariamente es Marina la que encarna este ámbito de acción. Conviene aquí emplear un término muy gráfico, pero que

\footnotetext{
25 Unamuno, M., Amor y pedagogía, op. cit., p. 350.

${ }^{26}$ Para una vinculación clara de la mujer con la tradición en la narrativa de Unamuno, véase el diálogo entre Avito y Fulgencio en el capítulo VII de Amor y pedagogía, op. cit., pp. 367-369, que incluye afirmaciones tales como: “¿No parece que sea la mujer la tradición y el hombre el progreso? [...] ¿ No resulta ser la mujer la memoria y el hombre el entendimiento de la especie?", etc. También es muy explícito en el Diario íntimo cuando afirma: "La mujer es la base de la tradición en las sociedades, es la calma en la agitación, el reposo en las luchas" (Unamuno, M., Diario intimo, en Obras Completas VII, Madrid, Fundación José Antonio de Castro, 2005, p. 278). También es pertinente el final de La tía Tula, op. cit., p. 897, cuando se muestra que la tradición se transmite por herencia espiritual a través de quienes no engendran carnalmente; herencia espiritual con rasgos evidentemente femeninos en el sentido aquí expuesto.

27 Unamuno, M., Amor y pedagogía, op. cit., p. 335.

${ }_{28}$ Cf. Unamuno, M., Abel Sánchez, op. cit., p. 779.

29 Cf. Unamuno, M. En torno al casticismo, op. cit., p. 81.
} 
resultará crucial en lo que resta: el amor es lo que tiene que ver con las entrañas, que María Zambrano calificó unamunianamente como «la sede del padecer» ${ }^{30}$. Esta cuestión es pertinente por un doble motivo. Primero, porque la maternidad y las entrańas están relacionadas de manera evidente; y segundo, porque en el pensamiento de Unamuno son las entrañas, y no el cerebro, el lugar en que se aloja quizá lo fundamental del ser humano (e incluso del pensamiento) ${ }^{31}$.

Estas alusiones a las entrańas como elemento nuclear humano (frente al racionalismo y el positivismo) permiten hablar de un "irracionalismo de Unamuno", el cual tiene mucho que ver con ese conocimiento que, alejado de la fría lógica y vinculado al instinto ${ }^{32}$, resulta necesario para vivir ${ }^{33}$. En último extremo, la piadosa Marina (que enseña a escondidas a sus hijos el temor de Dios y otros preceptos religiosos) encarna, precisamente, esa otra vertiente de nuestra existencia alejada de lo material y cuantificable que llega, no obstante, más lejos que la razón calculadora ${ }^{34}$.

El personaje de la tía Tula es probablemente el que mejor manifiesta el papel de la mujer en la concepción filosófica de Unamuno. Aunque su hermana Rosa es la que se termina casando y siendo madre (biológica), Tula es quien conquista y, lo que más interesa ahora, es la madre espiritual ${ }^{35}$ de los hijos de su hermana...

30 Zambrano, M., El hombre y lo divino, México, FCE, 2010, 188.

31 Cf. Unamuno, M., Del sentimiento trágico..., op. cit., p. 117.

32 Así ocurre con Antonia, esposa de Joaquín en Abel Sánchez y capaz de saber (sin atisbo de duda y de forma instintiva) los males de su marido (cf. Unamuno, M., Abel Sánchez, op. cit., p. 700). Véase también Diario intimo, op. cit., pp. 278-279, donde María es asiento de sabiduría (sedes sapientiae) y no de ciencia (sedes scientiae). En la misma línea, María Magdalena puede conocer sin tocar, de una manera que no es ni perceptiva ni propiamente racional como ocurre con Santo Tomás, que era varón; cf. La agonía del Cristianismo, op. cit., p. 75.

33 En muchas ocasiones, de manera poco rigurosa, se tiende a relacionar este "irracionalismo" con el de Kierkegaard. Desde luego, no cabe duda de la afinidad entre el pensador danés y su lector vasco (particularmente en el plano religioso; la referencia obligada es J. A. Collado, Kierkegaard y Unamuno: la existencia religiosa, Madrid: Gredos, 1962). No obstante, un análisis fino debe destacar que la afinidad no es necesariamente influencia: Unamuno ya tenía un posicionamiento fuerte antes de leer a Kierkegaard, si bien éste vino a corroborar su postura. En tal sentido, comparto la tesis central de J. C. Lago Bornstein, "Unamuno y Kierkegaard: dos espíritus hermanos", en Anales del Seminario de Metafísica, XXI, 1986, pp. 59-71. Asimismo, me parece necesario poner aquí de manifiesto la presencia (polémica, pero permanente) del pensamiento de William James en la filosofía unamuniana, desde ciertos aspectos de Pragmatismo, un nuevo nombre para viejas formas de pensar (Madrid: Alianza, 2007), hasta, y muy especialmente, La voluntad de creer (Barcelona: Marbot, 2009), donde se recoge una vertiente similar de este "irracionalismo" (lo entrecomillo a sabiendas de que hay cierta injusticia en llamar "irracional” a un ámbito del pensamiento sólo porque se halle más allá de las fronteras de la lógica formal; quizá sería mejor decir "arracional”). Sobre este último asunto es ineludible aludir a P. H. Fernández, Miguel de Unamuno y William James. Un paralelo pragmático, CIADA, Salamanca, 1961; o, de forma más reciente, a los trabajos de Izaskun Martínez, de la Universidad de Navarra (por ejemplo, I. Martínez, "El pragmatismo de Unamuno", en Anuario Filosófico, XL/2, 2007, pp. 435-450).

34 "El escepticismo, la incertidumbre, última posición a que llega la razón ejerciendo su análisis sobre sí misma, sobre su propia validez, es el fundamento sobre que la desesperación del sentimiento vital ha de fundar su esperanza” (M. de Unamuno, Del sentimiento trágico..., op. cit., p. 172). Esta aparente contradicción es lo que el campo religioso permite superar.

35 Cf. Unamuno, M., La tía Tula, op. cit., p. 843. 
y es madre también de su cuñado. Tal y como se ha planteado aquí el amor, no cabe duda de que este nivel de maternidad es posible: se trata de una maternidad no biológica, sino religiosa, virginal. Así, Tula es madre como un cura es "padre": espiritualmente ${ }^{36}$. Será también así como, siguiendo por ejemplo Cómo se hace una novela, la madre de los hijos de Unamuno devenga madre del propio Unamuno ${ }^{37}$. Más abajo reaparecerá esta cuestión a modo de cierre.

Para continuar con la caracterización de Tula es preciso explicitar algo obvio en la novela: el singular fervor religioso de este personaje. Habrá quien considere, y será justo en su juicio, que la ortodoxia religiosa del personaje es equivocada y le lleva a caer en fallas afectivas evidentes. El hecho, sin embargo, es que permite a Tula llevar una vida firme y perfectamente orientada, al menos hasta sus zozobras y arrepentimientos finales. Además, conviene recordarlo, Tula (y por supuesto su hermana Rosa) fueron criadas por su tío, un sacerdote bonachón mucho menos rígido que la siempre cortante y ácida protagonista -bien merece indicarse la "paternidad virginal" del tío para con las nińas, que se asocia en la novela en el culto de este hombre a tres mujeres: a la Virgen, a su madre y a su hermana (madre biológica de las chicas)-. Es él (pese a ser varón) quien enseña, especialmente a Tula, a ser madre virginalmente ${ }^{38}$.

Ya se ha señalado que Tula ejerce el papel de madre virginal, de guía vital para sus sobrinos-hijos y, en el fondo, para su cuñado. Ofrece, por lo tanto, una dimensión alternativa, aunque no incompatible, a la que ofrecía Marina: si ésta era la madre que daba amor antipositivista y compensaba con sus abrazos a la fría lógica con la que Avito trataba a su vástago, Tula supone la guía, la disciplina y la protección matriarcal (moral y física, como la que proporcionaba a San Manuel aquel nogal no casualmente calificado como "matriarcal", a cuya sombra jugaba de niño y con cuyo tronco hizo su ataúd ${ }^{39}$ ). Asimismo, Tula es la madre que se hace tal por amor

\footnotetext{
${ }^{36}$ Cf. Unamuno, M., La tía Tula, op. cit., p. 881 y San Manuel Bueno, mártir, op. cit., p. 313. Nótese que la posible paternidad espiritual llega en Unamuno a casos extremos. Sobre la paternidad y maternidad espirituales puede consultarse el cuento "Los hijos espirituales" (Unamuno, M., Cuentos, en Obras completas II, Madrid, Fundación José Antonio de Castro, 1995, pp. 587-591), en el que se hace ver en cierto modo a un hombre con rasgos materno-espirituales y a una mujer con rasgos paterno-espirituales: mientras Federico asume su "paternidad espiritual" amorosamente -de sus escritos y libros-, Eulalia crea como patología la "maternidad espiritual" de sus muńecos, a modo de compensación por su carencia de hijos carnales. Es por ello por lo que la relación entre ambos fracasa, cosa que no ocurre entre Federico y su madre (esforzada ella por favorecer la creatividad y labor de su hijo). Por otra parte, en el cuento "La carta del difunto" (Unamuno, M., Cuentos, op. cit., pp. 671-675), Jorge, difunto novio de Juana, hace que llegue a ésta una carta el día de su boda con Emilio, y en ella le dice: "Aunque nazca alguno de tus hijos, si es que los tienes, el día de San Jorge, no le pongas por nombre el mío, renuncio a la parte (espiritual se entiende) que en el angelito pueda yo tener" (p. 674). Incluso en estas circunstancias, pues, se asume que puede haber paternidad espiritual - por parte de un padre, dicho sea de paso, que cabe entender por el tono del relato que es virgen.

37 Cf. Cómo se hace una novela, en Obras completas VII, Madrid, Fundación José Antonio de Castro, 2005, p. 559.

${ }^{38}$ Cf. Unamuno, M., La tía Tula, op. cit., pp. 820-821.

39 Cf. Unamuno, M., San Manuel Bueno, mártir, op. cit., pp. 319-320 y 338.
} 
y no por biología. Eso sí, retomando algo que antes se ha señalado, lo hace como una Virgen madre y no como un Dios padre: pese a su frialdad y a su fuerte carácter para con sus pretendientes, se deshace al tratar con los niños. Es en este sentido en el que Pedro Ribas ha afirmado que "La pasión maternal de Tula [...] no es algo pasajero y superable, sino que es su ser entero. Tula es maternidad, igual que el médico Joaquín Monegro, personaje de Abel Sánchez, es envidia del pintor Abel" ${ }^{40}$.

Ángela Carballino, finalmente, abre una tercera vía de agencia religiosa de la mujer en el imaginario literario del pensador vasco. En San Manuel Bueno, mártir juega el papel explícito de ser la narradora (etimológicamente, "ángel" es "mensajero" ${ }^{41}$ ) de los hechos ocurridos en el pequeño pueblecito en que se desarrolla la trama pueblo, por cierto, que tiene en la obra un peso decisivo: en una literatura en la que la caracterización física de los personajes es prácticamente nula (especialmente de los femeninos, según Doyaga ${ }^{42}$ ), es el paisaje el que expresa los sentimientos y los gestos del alma de unos y de otros-.

Ahora bien, Ángela no es sólo una narradora al uso: es también la guardiana de un secreto y, en último extremo, una confidente. Esto permite, sin lugar a dudas, ejecutar un giro y decir de ella que es una confesora ${ }^{43}$ (como lo son también Tula ${ }^{44}$ y, en cierto modo, el perro Orfeo en Niebla: la confesión no es sólo algo que lleven a cabo sacerdotes). Así, Ángela es junto a su hermano Lázaro (otro nombre bien puesto) la persona que conoce el oscuro pesar de San Manuel.

Sobre el papel de Ángela como confesora puede mostrarse la profunda coherencia que la filosofía unamuniana mantiene en sus novelas. Tómese como referencia el ensayo de 1905 Soledad. En él Unamuno aprecia que sólo en soledad cabe alcanzar la verdad propia y ajena: al estar sin compañía se logra una cierta comunicabilidad con el otro que evita la posibilidad de la mentira ${ }^{45}$. Tal razonamiento encaja de forma absoluta con lo que hace Ángela Carballino en tanto que confesora: la distancia temporal de la muerte de San Manuel respecto de la narración es lo que permite hallar la verdad de fondo en la historia, pudiendo ver la vida del futuro santo sin que él mienta (adrede o no) al contarla. Adquiere así plena significación la capacidad angélica e incluso evangélica de Ángela y, por extensión, su agencia religiosa: es el ángel que trae la "noticia verdadera".

${ }_{40}$ Ribas, P., Unamuno. El vasco universal, Madrid, Endymion, 2015, p. 20.

${ }^{41}$ Cf. Unamuno, M., Niebla, op. cit., 484.

${ }^{42}$ Cf. Emilia Doyaga, "Unamuno ante la belleza femenina", en Cuadernos Hispanoamericanos, 229, 1969, p. 178.

${ }^{43}$ Cf. Unamuno, M., San Manuel Bueno, mártir, op. cit., 329.

${ }^{44}$ Cf. Unamuno, M., La tía Tula, op. cit., pp. 809-810.

${ }^{45}$ Cf. Unamuno, M., Soledad, en Obras completas VIII, Madrid, Fundación José Antonio de Castro, 2007, p. 783. 
Queda así indicada una triple dimensión activa de la feminidad en Unamuno desde el punto de vista religioso: es amor y consuelo ${ }^{46}$, es guía y disciplina, es confesora. A estas cabría añadir otras agencias religiosas derivadas de las señaladas y de la concepción unamuniana de la feminidad: la mujer puede redimir ${ }^{47}$ y evangelizar ${ }^{48}$; cumple votos sacerdotales como el de obediencia ${ }^{49}$; e incluso tiene la potestad de absolver pecados ${ }^{50}$. La agencia de la mujer en este ámbito está fuera de toda duda. Quedan así sentadas las condiciones para abrir dos cuestiones que hasta ahora habían permanecido deliberadamente al margen y que han de servir de cierre a esta investigación.

\section{La mujer en la vida de Unamunoः una esposa que exclama “Hijo mío!"}

EN PRIMER LUGAR, es conocida y, a la vez, polémica la cuestión sobre lo que Unamuno realmente creía o dejaba de creer en el ámbito religioso ${ }^{51}$. Sin embargo, su singular personalidad y la inmensa mayoría de sus escritos hacen plausible lo que dice de sí mismo en una célebre carta enviada a Federico Urales (pseudónimo de Juan Montseny) en torno a $1901^{52}$. En ella señala que ha vuelto a "cierto cristianis-

${ }^{46}$ La mujer como consuelo aparece también en la obra ensayística de Unamuno, encarnada en María Magdalena y en las mujeres que acompañan a Jesús en el Calvario; cf. Diario íntimo, op. cit., p. 293. Asimismo, Ángela en San Manuel Bueno, mártir, op. cit., p. 325 siente por San Manuel un afecto maternal que implicaba "aliviarle del peso de su cruz de nacimiento". También puede leerse en este sentido el pasaje en que Tulio Montalbán considera que su único consuelo es volver al seno materno, lo que da pie a Julio Macedo a explícitamente entenderlo así y a la posterior reflexión entre Elvira Jacquelot y su padre al final de la obra (cf. Unamuno, M., Tulio Montalbán y Julio Macedo, en Obras completas II, Madrid, Fundación José Antonio de Castro, 1995, pp. 171 y 184-185). Por su parte, también San Manuel es presentado como agente que proporciona consuelo, pero justamente en la medida en que tiene rasgos unamunianamente "femeninos"; cf. Unamuno, M., San Manuel Bueno, mártir, op. cit., pp. 315-316.

47 Cf. Unamuno, M., Abel Sánchez, op. cit., p. 765.

${ }^{48}$ Cf. Unamuno, M., Abel Sánchez, p. 726 y Ricardo Senabre, "Introducción" a Obras completas I, op. cit., p. XXIII.

${ }^{49}$ Cf. Unamuno, M., Diario intimo, op. cit., 296; y La tía Tula, op. cit., p. 872.

${ }^{50}$ Cf. Unamuno, M., San Manuel Bueno, mártir, op. cit., p. 333. En este pasaje, Ángela absuelve en nombre del pueblo, y no sólo de Dios padre, hijo y espíritu santo, a San Manuel mientras a ella se le "estremecían las entrańas maternales" por sentirse "penetrada de un misterioso sacerdocio". Y es relevante que lo haga en nombre del pueblo, pues es hacia el pueblo hacia el que ha volcado su vida San Manuel y, por tanto, con quien debe saldar cuentas antes que con la divinidad. Cabe señalar que esta orientación del individuo hacia el pueblo es una característica propia del héroe en sentido unamuniano -junto con el ya mencionado saber no estrictamente científico que tantas mujeres tienen en la obra unamuniana-, y que tiene sentido en la medida en que San Manuel encarna en buena parte ese ideal heroico.

51 Una recopilación algo anticuada de las posiciones al respecto puede leerse en: Baker, A. F., "Unamuno and the Religion of Uncertainty", en Hispanic Review, vol. 58, No 1 (Winter, 1990), pp. 37-56.

52 Urales, F., La evolución de la filosofía en España, Barcelona, Laia, 1977, pp. 160-163; también disponible en Padilla Novoa, M., Unamuno (1864-1936), Madrid, Ediciones del Orto, 2001, pp. 46-48. 
mo sentimental, algo vago, al cristianismo llamado protestantismo liberal" 53 . Traer esta afirmación a colación, aunque sea muy de pasada, permite simplemente aludir al diferente papel que desempeña o puede desempeñar la mujer en el aspecto doctrinal y sacerdotal dentro del ámbito protestante, algo que encaja en cierto modo con los planteamientos aquí expuestos.

En segundo y último lugar, con el fin de redondear el argumento sostenido en estas páginas, debe indicarse que la propuesta unamuniana en torno a la agencia religiosa de la mujer no es sólo un producto teórico literario carente de significación en el mundo de los hechos. Se suele decir que Unamuno utiliza a sus personajes para poner en discusión ideas que en su cabeza no tienen perfecta claridad, para aclararse a sí mismo ${ }^{54}$, dejando que dichas ideas corran libres (así se explica que Augusto, en la celebérrima obra Niebla, se rebele contra el propio Unamuno, al que va a visitar); sólo cuando termina la novela está en disposición de pensar "filosóficamente" 55 .

La reflexión anterior sobre la vida propia de los personajes es cierta, y en buena medida encaja con otras doctrinas del autor vasco (el cual llegará a afirmar que Cervantes es menos real que el Quijote). Sin embargo, la reflexión a que me he referido omite que algunas de las cuestiones fundamentales de las obras unamunianas no son fruto de su imaginación, sino de su recuerdo, o al menos están inspiradas por éste. Tal es el caso, por ejemplo, de los sucesos bélicos de su niñez que inspiraron Paz en la guerra; también la muerte de su hijo Raimundo, insinuada en ciertos pasajes de Amor y pedagogía. Así, hay acontecimientos biográficos de Unamuno que resultan determinantes para entender el papel religioso de la mujer y su caracterización como madre no necesariamente biológica en el sentido que aquí se ha expuesto.

Ya desde niño, la presencia femenina resulta esencial en la vida de Unamuno: su padre falleció en 1870, cuando el futuro escritor apenas tenía seis años, quedando al cuidado de su madre y de su abuela Benita. Este dato, aparentemente anecdótico, se ve reforzado en el año 1897 , concretamente en una noche de marzo ${ }^{56}$ : presa de

53 Es obligado remitir aquí al estudio que realizó Orringer sobre la influencia de los autores protestantes liberales en la obra unamuniana y, en particular, en Del sentimiento trágico de la vida..., aunque notando que esta carta es de 1901 y que el estudio de Orringer se centra en un periodo diez años posterior: N. R. Orringer, Unamuno y los protestantes liberales (1912). Sobre las fuentes de "Del sentimiento trágico de la vida", Madrid, Gredos, 1985.

54 Un análisis de este planteamiento respecto a los personajes femeninos de La tía Tula y San Manuel Bueno, mártir - con el que cabe establecer ciertas polémicas, pese a su notable calidad- fue llevado a cabo por Gaytán, R., Los personajes femeninos en las novelas de Unamuno, A thesis submitted in partial fullfillment of the requirements for the Degree Master of Arts, Rice University, Houston, Texas, 1996.

55 En último extremo, sobre esta cuestión gira buena parte de Cómo se hace una novela, quizá el texto más extraño, y a la vez más sugerente, de don Miguel.

56 Según una edición de Amor y pedagogía (Madrid, Alianza, 2008, p. 163, nota 1), el episodio tuvo lugar el 23 de marzo de 1897. 
una profunda angustia, zarandeado por la vida ${ }^{57} \mathrm{y}$ atravesado por un drama interno permanente, Unamuno sufre una gravísima crisis de fe que cambiará su vida y sus intereses para siempre ${ }^{58}$.

Lo que ahora interesa de este episodio bien conocido no son las consecuencias más obvias que tuvo, sino un hecho aparentemente trivial. Ante la congoja sufrida, don Miguel se abrazó a su esposa, Concepción Lizárraga, entre lágrimas, y es la respuesta de ésta la que dota de significado a cuanto se ha venido diciendo: ella respondió al abrazo exclamando “Hijo mío!". No le llama "esposo”, sino "hijo”; así como Tula se convierte en madre de su cuñado, Concepción Lizárraga amadrina a su esposo de manera salvífica, convirtiéndose en imagen viva de esa Virgen de la que Unamuno nunca quiso volver a separarse ${ }^{59}$ : su esposa se convirtió en una nueva Abisag la sunamita ${ }^{60}$. El episodio aparece recogido en muchos lugares de la narrativa unamuniana ${ }^{61}$, y refleja el amor materno (biológico o no) al que dan forma los personajes que aquí se han expuesto. A la vez, Unamuno intenta construir un sistema teórico que dote de densidad a la mujer en el esquema religioso que subyace a todo ser humano ${ }^{62}$. Así se aprecia en Vida de Don Quijote y Sancho, cuando afirma:

"Don Quijote dudó por un momento de la Gloria, pero ésta, su amada, le amaba a su vez ya y era, por tanto, su madre, como lo es del amado toda su amante verdadera. Hay quien no descubre la hondura toda del cariño que su mujer le guarda sino al oírla, en momento de congoja, un desgarrador ¡hijo mío!, yendo a estrecharle maternalmente en sus

\footnotetext{
57 A la hidrocefalia que padecía su hijo Raimundo se sumaba una situación económica precaria y otros acontecimientos, como la acusación -en el mejor de los casos, sospechosa- a sus compañeros de la revista Ciencia social de estar detrás de los atentados del Corpus Christi, acontecimiento que daría lugar al conocido Proceso de Montjuic.

58 Para un resumen breve (aunque completo) de los condicionantes y consecuencias de esta crisis, cf. Padilla Novoa, M., Unamuno, filósofo de encrucijada, Madrid, Cincel, 1985, pp. 62-64. También es relevante la p. 51 de la citada obra, donde se alude a los orígenes relativamente incestuosos del propio Unamuno: su madre era, a la vez, la sobrina de su padre.

59 En su Diario intimo se lee: "He llegado hasta el ateísmo intelectual, hasta imaginar un mundo sin Dios, pero ahora veo que siempre conservé una oculta fe en la Virgen María. En momentos de apuro se me escapaba maquinalmente del pecho esta exclamación: Madre de Misericordia, favoréceme" (Unamuno, M., Diario intimo, op. cit., p. 278).

${ }^{60}$ Cf. La agonía del Cristianismo, op. cit., p. 54.

${ }^{61}$ Cf. Unamuno, M., Abel Sánchez, op. cit., p. 709; Amor y pedagogía, op. cit., p. 422; Cómo se hace una novela, op. cit., p. 594; La tía Tula, op. cit., pp. 823 y 825 (varias veces de manera indirecta); Niebla, op. cit., p. 506-507 e indirectamente 548-549, donde Avito Carrascal le cuenta a Augusto cómo Marina se ha hecho su madre tras perder a Apolodoro; San Manuel Bueno, mártir, op. cit., pp. 323 y 317, aunque aquí es la madre biológica la que lo grita, evidenciando que el sentimiento matriarcal biológico es igual que el espiritual y viceversa; el cuento "Un cuentecillo sin argumento", en Cuentos, op. cit., p. 693; etc. Resulta coherente lo irritante que es la expresión cuando la pronuncia un hombre: cf. Abel Sánchez, op. cit., p. 743: Federico se lo dice hasta tres veces a Joaquín.

${ }^{62}$ Hay incluso una dimensión política del asunto. Véase, por ejemplo, la contraposición a la patria que supone la matria en el "Prólogo (que puede saltar el lector de novelas)" a La tía Tula, op. cit., pp. 800-802; y cómo España es madre e hija de Unamuno según Cómo se hace una novela, op. cit., p. 562 y La agonía del Cristianismo, op. cit., p. 143.
} 
brazos. Todo amor de mujer es, si verdadero y entrañable, amor de madre; la mujer prohíja a quien ama. Y así Dulcinea es ya madre espiritual, no tan sólo señora de los pensamientos, de Don Quijote, y aunque se le hubiese a éste pasado por las mientes desahijarse de ella, veréis que ella le recobra con amoroso reclamo, como al ternerillo recental que corre a triscar suelto le requerencia la vaca al sentirse con las ubres perinchidas, rompiendo con dulce arrullo el aire que los separa. Veréis cómo le detiene con verdes lazos" ${ }^{63}$.

Era preciso finalizar este texto retomando, de nuevo, Vida de Don Quijote y Sancho. En esta obra Unamuno cuenta no lo que Don Quijote y Sancho fueron haciendo, sino lo que pensaron y lo que sintieron. En muchas ocasiones, el autor se remite a la vida y obra de Ignacio de Loyola, cuyo paralelismo con la obra cervantina no es desconocida; por supuesto, el Cid aparece también mencionado en numerosas ocasiones; pero, y esto es lo significativo, no les anda a la zaga en referencias Santa Teresa de Ávila (que aparece en el "Prólogo" a La tía Tula como "Santa Madre y Tía" ${ }^{64}$ y proporciona el motto a La agonía del Cristianismo): que Unamuno piense en ella, una mujer "madre espiritual", al leer el Quijote, poniéndola a la altura del mismo, es quizá la corroboración máxima de la reivindicación de lo femenino en el marco religioso por parte del autor.

${ }_{63}$ M. de Unamuno, Vida de Don Quijote y Sancho, op. cit., p. 210.

${ }^{64}$ Unamuno, M., La tía Tula, op. cit., p. 797. 


\section{REFERENCIAS Bibliográficas}

Baker, A. F., "Unamuno and the Religion of Uncertainty", en Hispanic Review, vol. 58, No 1 (Winter, 1990), pp. 37-56.

Collado, J. A., Collado, Kierkegaard y Unamuno: la existencia religiosa, Madrid, Gredos, 1962.

Doyaga, E., "Unamuno ante la belleza femenina", en Cuadernos Hispanoamericanos, 229, 1969, p. 178-184.

Fernández, P. H., Miguel de Unamuno y William James. Un paralelo pragmático, CIADA, Salamanca, 1961.

Gaytán, R., Los personajes femeninos en las novelas de Unamuno, A thesis submitted in partial fullfillment of the requirements for the Degree Master of Arts, Rice University, Houston, Texas, 1996.

James, W., Pragmatismo, un nuevo nombre para viejas formas de pensar, Madrid, Alianza, 2007.

James, W., La voluntad de creer, Barcelona, Marbot, 2009.

Lago Bornstein, J. C., "Unamuno y Kierkegaard: dos espíritus hermanos", en Anales del Seminario de Metafisica, XXI, 1986, pp. 59-71.

Martínez, I., "El pragmatismo de Unamuno", en Anuario Filosófico, XL/2, 2007, pp. 435-450.

Morales Galán, C., El tema maternal en la concepción unamunesca de la mujer, Tesis doctoral, Louisiana State University and Agricultural and Mechanical College, 1971.

Orringer, N. R., Unamuno y los protestantes liberales (1912). Sobre las fuentes de "Del sentimiento trágico de la vida", Madrid, Gredos, 1985.

Pacheco, B., "La concepción de lo femenino en Unamuno: encuentro en un entreacto", en Contexto, Segunda Etapa, volumen 8, no 10, 2004, pp. 217-228.

Padilla Novoa, M., Unamuno, filósofo de encrucijada, Madrid, Cincel, 1985.

Padilla Novoa, M., Unamuno (1864-1936), Madrid, Ediciones del Orto, 2001.

Ribas, P., Unamuno. El vasco universal, Madrid, Endymion, 2015.

Sandoval Ullán, A., «El concepto de mujer en el pensamiento de Miguel de Unamuno", en Cuadernos de la Cátedra Miguel de Unamuno, 39, 2004, pp. 27-60. 
Unamuno, M., Obras completas I, Madrid, Escelicer, 1967.

Unamuno, M., Obras completas III, Madrid, Escelicer, 1968.

Unamuno, M., Obras completas I, Madrid, Fundación José Antonio de Castro, 1995.

Unamuno, M. Obras completas II, Madrid, Fundación José Antonio de Castro, 1995.

Unamuno, M., Obras completas VII, Madrid, Fundación José Antonio de Castro, 2005.

Unamuno, M., Obras completas VIII, Madrid, Fundación José Antonio de Castro, 2007.

Unamuno, M., La agonía del Cristianismo, Madrid: Espasa-Calpe, 1966.

Unamuno, M., La tía Tula, Barcelona, Bibliotex SL, 2001.

Unamuno, M., Amor y pedagogía, Madrid, Austral, 2007.

Unamuno, M., Amor y pedagogía, Madrid, Alianza, 2008.

Unamuno, M., La tía Tula, Madrid, Alianza, 2012.

Urales, F., La evolución de la filosofía en España, Barcelona, Laia, 1977.

Zambrano, M., El hombre y lo divino, México, FCE, 2010.

DOI: https://doi.org/10.15366/bp.2020.24.002

Bajo Palabra. II Época. No 24. Pgs: 37-54 